\title{
MOSQUITOES (DIPTERA: CULICIDAE) OF THE WESTERN COASTAL AREA, KINGDOM OF SAUDI ARABIA: SPECIES COMPOSITION, ABUNDANCE, DIVERSITY AND MEDICAL IMPORTANCE By
}

\author{
MOSTAFA I. HASSAN ${ }^{1}$, MOHAMED A. KENAWY ${ }^{2 *}$, HAMDY A. AL ASHRY ${ }^{3}$ \\ AND MOHAMMED SHOBRAK ${ }^{4}$
}

Department of Zoology, Faculty of Science (boys), Al-Azhar University, Nasr City, Cairo ${ }^{1}$, Department of Entomology, Faculty of Science, Ain Shams University, Cairo $11566^{2}$, TRAP Pest Control and Garden Maintenance Co. Ltd., Jeddah, Saudi Arabia $^{3}$, and Department of Biology, Science College, Taif University, Taif 21974, Kingdom of Saudi Arabia ${ }^{4}$ ( ${ }^{*}$ Correspondence: mohamedkenawy330@gmail.com)

\begin{abstract}
An entomological survey was undertaken for two years to update the mosquito fauna of the 3 regions (Mecca, Al Madinah and Tabouk), of the western coast, Kingdom of Saudi Arabia. Six localies representing such Regions (Taif, Mecca, Jeddah, Yanbu, Daba and Haql) were sampled for larvae and adults. Nineteen species of six genera were reported of which genus Culex $(57.89 \%$ sp.) were the most common followed by Anopheles $(21.05 \%)$ and Stegomyia, Ochlerotatus, Aedes and Culesita (5.26\% each). Three species (Cx. sitiens, Cx. torrentium and Am. v. arabiensis) were new reports in study area. A total of 10930 larvae and 33108 adults were collected of which those representing genus Culex were predominating (92.74\% larva, $93.46 \%$ adult). Of the reported species, $C x$. quinquefasciatus (47.11\% larva, $57.52 \%$ adult) and Cx. pipiens (22.24\% larva, $27.42 \%$ adult) were the common ones. Both Taif and Tabouk reported the highest number of species (13 sp., 68.42\%), followed by Jeddah (12 sp., 63.16\%), Mecca (10 sp., 52.63\%) and Yanbu (8 sp., 42.11\%). Tabouk represented the maximum diversity with the highest Simpson index $(1-\mathrm{D}=0.65)$ and Shannon index $(\mathrm{H}=1.25)$ followed by Taif (1- $\mathrm{D}=0.54, \mathrm{H}=1.01)$. Per sampling site, Jeddah reported the highest number of larvae (313.70), and Mecca had the highest adult number (670.18). A complete list of mosquito fauna of the western coast including $35 \mathrm{spp}$. was presented based on the present and previous surveys. The role of the reported mosquito species as disease vectors was discussed. The study concluded that the diversity and abundance of the different mosquito species, among which several vectors of diseases mainly malaria, Rift Valley fever, lymphatic filariasis and dengue fever may pause a risk of transmission and more spread of such disease in this part that contains the holy places which are visited all year round by millions of people from several countries.
\end{abstract}

Key words: Mosquito fauna, Species diversity, Mosquito larvae, Mosquito adults, Relative abundance, Saudi Arabia.

\section{Introduction}

The Kingdom of Saudi Arabia " $16^{\circ} \& 33^{\circ}$ N, $34^{\circ} \& 56^{\circ}$ E" (Wikipedia: https://en.Wi kipedia.org/wiki/KSA) occupies about $80 \%$ of the Arabian Peninsula with an area of $2,149,690 \mathrm{Km}^{2}$ \& a population of 30,770 , 375 (2014 estimate). Saudi Arabia's geography is dominated by the Arabian Desert and associated semi-desert. The Western Region (the Hijaz) of the Kingdom includes the west coast, north of Asir. It contains the mountain chain (with peaks rising to 3,000 meters), running south to north and decreasing gradually in elevation as it moves northward, and the coastal plain bordering the Red Sea. It also includes the city of Jeddah; it is the main port for thousands of pilgrims arrive annually as the first step on their trip to Holy cities of Mecca (to the east) and Al Madinah (to the north). In the mountains above Mecca and Jeddah is the town of Taif. Its elevation gives it a climate far cooler than either Jeddah or Mecca and without the uncomfortable humidity of the former cities. The coastal area of the Western Region is notorious for its humidity, with summer temperatures rising to above $40^{\circ} \mathrm{C}$. Mosquitoes of the different parts of Saudi Arabia were investigated through several surveys conducted by many workers 
(Mattingly and Knight, 1956; Büttiker, 1981; Wills et al, 1985; Jupp et al, 2002; Miller et al, 2002; Abdoon and Alshahrani, 2003; Abdoon, 2004; Alahmed et al, 2007; Alahmed, 2012). As a result of these surveys, fifty three species belonging to 11 genera: Anopheles (19 spp.), Culex (22), Ochlerotatus (3), Culiseta (2) and one species each of Lutzia, Stegomyia, Aedes, Aedimorphus, Fredwardsius, Uranotaenia and Orthopodomyia were reported. In addition, some of scattered surveys were conducted in the western part of the Kingdom (Abdullah and Merdan, 1995; AI Ali et al, 2008; Al Ghamdi et al, 2008; Alahmed et al, 2009; Al Ahmed et al, 2010; Kheir et al, 2010; Al Ahmad et al, 2011; Khater et al, 2013; Al Ashry et al, 2014; Alikhan et al, 2014; Bakr et al, 2014; Mahyoub et al, 2015). Several species mainly: An. arabiensis, An. stephensi, An. sergenti, An. fluviatilis, An. multicolor, Cx. pipiens, Cx. quinquefasciatus, $C x$. tritaeniorhynchus, $C x$. perexiguus, St. aegypti and Am. v. arabie- nsis are involved in transmission of several diseases. The most common mosquitoborne diseases include filariasis (Sebai et al, 1974; Omar, 1996; Haleem et al, 2002), RVF (Jupp et al, 2002; Miller et al, 2002; Al-Hazmi et al, 2003; Balkhy and Memish, 2003; Madani et al, 2003; Flick and Bouloy, 2005; Elfadil et al, 2006; Al-Qabati and AlAfaleq, 2010), malaria (Warrel, 1993; AlSeghayer et al, 1999; Abdoon and Alshahrani, 2003; Al-Tawfiq, 2006) and dengue fever (Fakeeh and Zaki, 2001; 2003; Ayyub et al, 2006; Khan et al, 2008; El-Gilany et al, 2010; Aziz et al, 2014). For the past few decades, Saudi Arabia has witnessed tremendous advances in social development and urbanization in almost all Regions (Alahmed, 2012) which presumably have affected the insect fauna, particularly mosquitoes (Al Ahmed et al, 2010). Thus, the present work was planned to update the species composition and distribution of mosquitoe fauna in the different regions representing the western part/coast of Saudi Arabia.

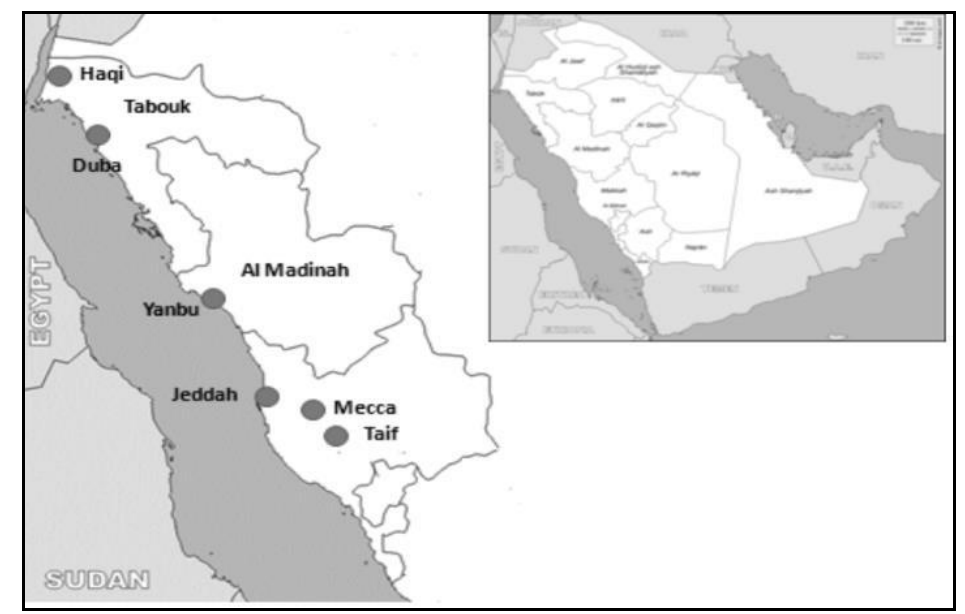

Fig. 1: Map of Saudi Arabia showing study localities in western part

\section{Materials and Methods}

The study was carried out in the three regions of the western part of the Kingdom namely Mecca, Al Madinah and Tabouk (Fig. 1).

The Mecca Region (Makah) " $21^{\circ} 25^{\prime} \mathrm{N}$, $39^{\circ} 49^{\prime} \mathrm{E}$ " is the most populous region in Saudi Arabia. In this region the study included Mecca, the capital and 2 large cities, Jeddah \& Taif. Mecca or Makah ' $21^{\circ} 30^{\prime} \mathrm{N}$, $41^{\circ} 0$ 'E" is located in a narrow valley at a height of $277 \mathrm{~m}$ above sea level. It occupies an area of $153,148 \mathrm{~km}^{2}$. Its resident population is $6,915,006$ (2010 census). In addition, more than triple this number of the visitors comes every year during the Hajj (Pilgrimage) period. Mecca features a hot desert climate. Jeddah " $21^{\circ} 32^{\prime} 36^{\prime \prime} \mathrm{N}, 39^{\circ} 10^{\prime} 22^{\prime \prime} \mathrm{E}$ " is the largest sea port on the Red Sea, and the second-largest city in Saudi Arabia after 
the capital, Riyadh with a population of 3.4 million (2007 Census) and an area of $1,600 \mathrm{~km}^{2}$. Jeddah features an arid climate. Taif " $21^{\circ} 26^{\prime} \mathrm{N}, 40^{\circ} 21^{\prime} \mathrm{E}$ " is a city at an elevation of $1,879 \mathrm{~m}$ on the slopes of AlSarawat mountains. The city is the centre of an agricultural area known for its grapes, figs, roses and honey. Taif has a hot desert climate, with hot summers and mild winters. The Al Madinah (Al-Madīnah al-Munawarah) Region " $25^{\circ} 0$ ' N, $39^{\circ} 30 \mathrm{E}$ " is located along the Red Sea coast. It has an area of $151,990 \mathrm{~km}^{2}$ and subdivided into seven governorates. The study was carried out in Yanbu (Yanbu'al Bahr) " $24^{\circ} 05^{\prime} \mathrm{N}, 38^{\circ} 00^{\prime} \mathrm{E}$ " which is a major Red Sea port approximately 300 kilometers northwest of Jeddah. A large number of the residents are foreign expatriates working in the oil refineries and petro-chemical industry. Tabouk (Tabuk) Region " $28^{\circ} 0^{\prime} \mathrm{N}, 37^{\circ} 0^{\prime} \mathrm{E}$ " is located along the north-west coast of the country, facing Egypt across the Red Sea. It has an area of $146,072 \mathrm{~km}^{2}$. The study was carried out inHaql and Duba. Haq1 “ $29^{\circ} 17^{\prime} \mathrm{N}, 34^{\circ} 56^{\prime} \mathrm{E}$ ” is a town near the head of the Gulf of Aqaba, adjacent to Aqaba across the Jordanian border with a small population of 25,000. Duba ' $27^{\circ} 20^{\prime} 57.3^{\prime \prime} \mathrm{N}, 35^{\circ} 41^{\prime} 46.2$ "E" is a small port city on the northern Red Sea coast. Duba has a population of about $22,000 \&$ a hot desert climate. The study included a total of 28 sites in the 6 localities (Taif: 21, Mecca: 11, Jeddah: 20, Yanbu: 9, Haql: 11, Duba: 10). Each site was biweekly surveyed during the period from January 2013 to December 2014. In each site, inspections of the water bodies for mosquito larvae were carried out using a plastic dipper, $125 \mathrm{~mm}$ in diameter with a 90 $\mathrm{cm}$ aluminum telescoping handle. Three samples of 10 dips (a survey unit, SU) per breeding site were taken. Collected larvae were placed in labeled plastic bags (Nasco whirl pack 4002 filline USA) and transported to the laboratory in a picnic ice box containing cold water to prevent overheating. At the laboratory, $3^{\text {rd }}$ and $4^{\text {th }}$ larval instars were killed with hot water and preserved in labeled specimen tubes containing $70 \%$ ethanol to be ready for identification. Adults were collected using three different types of traps: (1) the CDC (Center for Disease Control) miniature light traps (Model 512, John W. Hock Co., Gainesville, FL, USA), (2) the V-Mart Super photocatalyst "Black Hole (BH) traps" (Venus Technology Co., Ltd. Wangthonglang, Bangkok, Thailand) and (3) the CDC Fay-Prince Blacklight (UV) Trap (Model 812, John W. Hock Company, Gainesville, Florida, USA). The traps were set before sunset and collected after sunrise next morning. A total of 329, 1350 and $484 \mathrm{CDC}, \mathrm{BH}$, and UV traps, respectively were used in all the study localities during the study period. The collected mosquitoes were aspirated, placed in labeled paper cups that kept in a picnic ice box while being transported to the laboratory. In the laboratory, mosquitoes were preserved in $70 \%$ alcohol till identification. Larvae and adults were identified according to keys ofMattingly and Knight (1956), Glick (1992) and Al Ahmad et al. (2011).

Data analysis: Data obtained during 2013 and 2014 were compiled altogether. The species diversity of the mosquito adults based on the Simpson (1-D) and Shannon $(\mathrm{H})$ indices was examined for the different localities. The PAST (Paleontological Statistics Version 2.08; Hammer et al, 2001) computerized software was used.

\section{Results and Discussion}

The present study is a report of the results of entomological surveys of mosquito fauna in the different regions representing the western part/coast of Saudi Arabia. A total of 19 species belonging to 6 genera (Culex, Anopheles, Stegomyia, Ochlerotatus, Aedi The present study is a report of the results of entomological surveys of mosquito fauna in the different regions representing the western part/coast of Saudi Arabia. A total of 19 species belonging to 6 genera (Culex, Anopheles, Stegomyia, Ochlerotatus, Aedimorphus and Culiseta) were reported (Tab. 
1), these were: $C x$. pipiens, $C x$. perexiguus, $C x$. sinaiticus, $C x$. quinquefasciatus, $C x$. tritaeniorhynchus, $C x$. theileri, $C x$. sitiens, $C x$. torrentium, $C x$. simpsoni, $C x$. Iaticinc-

Table 1: Species composition and distribution of the reported mosquito species

\begin{tabular}{|c|c|c|c|c|c|c|}
\hline 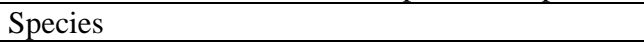 & Taif & Mecca & Jeddah & Yanbu & Tabouk & All \\
\hline Culex (Culex) pipiens L. & $\bullet$ & $\bullet$ & $\bullet$ & $\bullet$ & $\bullet$ & $\bullet$ \\
\hline Cx. (Cux.) perexiguus Theobald & $\bullet$ & $\bullet$ & $\bullet$ & $\bullet$ & $\bullet$ & $\bullet$ \\
\hline Cx. (Cux.) sinaiticus Kirkpatrik & $\bullet$ & & $\bullet$ & $\bullet$ & $\bullet$ & $\bullet$ \\
\hline Cx. (Cux.) quinquefasciatus Say & $\bullet$ & $\bullet$ & $\bullet$ & $\bullet$ & $\bullet$ & $\bullet$ \\
\hline Cx. $($ Cux.) tritaeniorhynchus Giles & & $\bullet$ & $\bullet$ & $\bullet$ & $\bullet$ & $\bullet$ \\
\hline Cx. (Cux.) theileri Theobald & $\bullet$ & & $\bullet$ & & $\bullet$ & $\bullet$ \\
\hline Cx. (Cux.) sitiens Wiedemann & & & $\bullet$ & $\bullet$ & $\bullet$ & $\bullet$ \\
\hline$C x .($ Cux.) torrentium Martini & & $\bullet$ & $\bullet$ & & & $\bullet$ \\
\hline Cx. (Cux.) simpsoni Theobald & $\bullet$ & & & & $\bullet$ & $\bullet$ \\
\hline Cx. (Cux.) laticinctus Edwards & $\bullet$ & $\bullet$ & $\bullet$ & $\bullet$ & & $\bullet$ \\
\hline Cx. (Barraudius) pusillus Macquart & $\bullet$ & & & & & $\bullet$ \\
\hline Anopheles (Cellia) dthali Patton & $\bullet$ & $\bullet$ & $\bullet$ & & & $\bullet$ \\
\hline An. (Cel.) multicolor Cambouliu & $\bullet$ & & & & $\bullet$ & $\bullet$ \\
\hline An. (Cel.) sergentii Theobald & $\bullet$ & & & & & $\bullet$ \\
\hline An. (Cel.) fluviatilis James & & & & & $\bullet$ & $\bullet$ \\
\hline Stegomyia (St.) aegypti (L.) & $\bullet$ & $\bullet$ & $\bullet$ & $\bullet$ & $\bullet$ & $\bullet$ \\
\hline Ochlerotatus (Oc.) caspius (Pallas) & & $\bullet$ & $\bullet$ & & $\bullet$ & $\bullet$ \\
\hline Aedimorphus vexans arabiensis (Patton) & & $\bullet$ & & & & $\bullet$ \\
\hline Culiseta (Allotheobaldia) longiareolata Macquart & $\bullet$ & & & & $\bullet$ & $\bullet$ \\
\hline Total number of species & 13 & 10 & 12 & 8 & 13 & 19 \\
\hline
\end{tabular}

According to the previous surveys in the western part (AI Ali et al, 2008, Al Ghamdi et al, 2008; Alahmed et al, 2009; Kheir et al, 2010; Al Ahmad et al, 2011; Khater et al, 2013; Alikhan et al, 2014; Mahyoub et al, 2015), 17 species were missed during the present study. These are: $C x$. duttoni, $C x$. decens, Cx. arbieeni, Lutzia tigripes, An. culicifacies, An. gambiae, An. turkhudi, An. pharoensis, An. subpictus, An. stephensi, An. rhodesiensis, An. azaniae, An. cinereus, An. pretoriensis, Oc. detritus, Fredwardsius vittatus and Uranotaenia unguiculata. Moreover, three species (Cx. sitiens, Cx. torrentium and Am. v. arabiensis) were not encountered before so that they may be considered a new report in the western part of the Kingdom. However, these 3 species were reported to be present in the neighboring region of Asir (Miller et al, 2002; Al Ahmad et al, 2011; Al Ashry et $a l, 2014)$. Consequently, the mosquito fauna of the western part/coast comprises 36 species: 14 Anopheles, 14 Culex, two Ochlerotatus, and one species each of Lutzia, Stegomyia, Aedimorphus, Fredwardsius, Culiseta and Uranotaenia (Tab. 2). The distribu- tus, Cx. pusillus, An. dthali, An. multicolor, An. sergentii, An. fluviatilis, St. aegypti, Oc. caspius, Am. v. arabiensis and Cs. longiareolata.

tion, number of the reported species and relative abundance of larvae and adults (mean number of larvae /adults per sampling site) varied in the surveyed localities. Both Taif and Tabouk reported the highest number of species (13 sp., 68.42\%), followed by Jeddah (12 sp., 63.16\%), Mecca (10 sp., $52.63 \%$ ) and Yanbu (8 sp., 42.11\%) (Tab.1). The species diversity for the mosquito adults sampled during the study period in the different localities (Fig. 2) reflected similar findings. The results revealed maximum diversity in Tabouk with the highest Simpson index $(1-\mathrm{D}=0.65)$ and Shannon index $(\mathrm{H}=1.25)$ followed by Taif (1-D=0.54, $\mathrm{H}=1.01)$ due to the high richness of the species in the two localities ( $n=13 / 19$ sp.) whereas, Mecca $(1-\mathrm{D}=0.48, \mathrm{H}=0.94)$ and Yanbu ( $1-\mathrm{D}=0.44, \mathrm{H}=0.94)$ represented the areas with the minimum diversity indices due to their minimum richness $(\mathrm{n}=10$ and 8 sp., respectively). On the other hand, Jeddah exhibited intermediate values ( $1-\mathrm{D}=0.49$ and $\mathrm{H}=0.99$ ). This may be attributed mainly to climate prevailing in Tabouk and Taif of being much cooler during the summer time than it is in other parts of Saudi Arabia 
(Wikipedia:https://en.wikipedia.org/wiki/KS A), for example Mecca and Jeddah which retains their warm temperatures in winter and summer temperatures are extremely hot, often breaking $40^{\circ} \mathrm{C}$ (Mecca) or $43^{\circ} \mathrm{C}$ (Jeddah) in the afternoon and dropping to $30^{\circ} \mathrm{C}$ in the evening. However, Al-Ahmad et al. (2011) indicated that out of 25 reported species, 17 were reported in both Jeddah and Mecca, 15 in Taif, 12 in Madinah and only 8 in Tabouk.

Table 2: Mosquito fauna of the western part of Saudi Arabia (Present survey: A, Previous surveys: B)

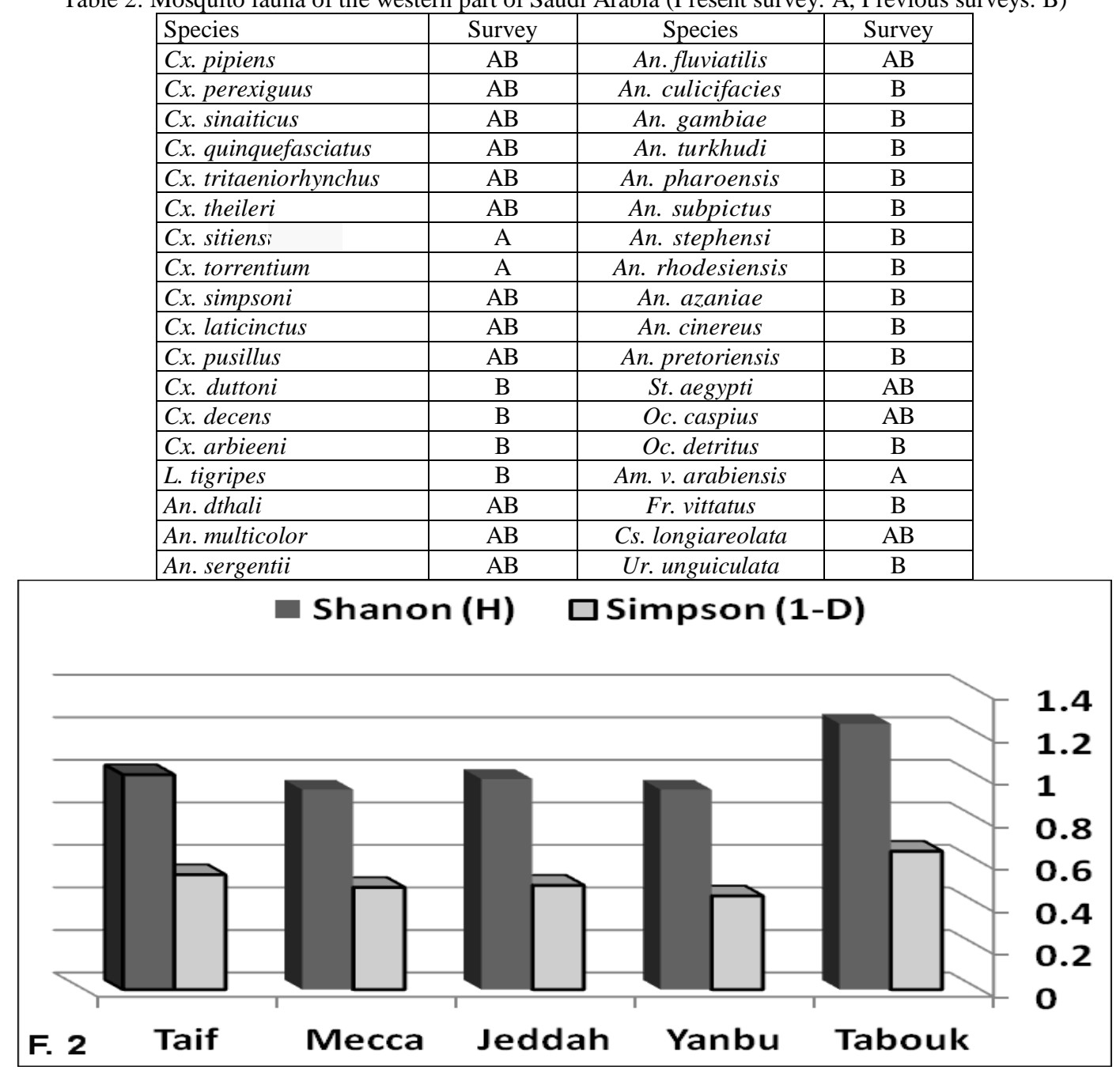

Fig. 2: Diversity indices for collected mosquito adults

Based on the mean number of larvae and adults per sampling site (Fig. 3), Jeddah reported the highest number of larvae (313.70) followed by Taif (118.10), Yanbu (112.56), Mecca (69.82) and Tabouk (18.81). Regarding adults, Mecca reported the highest number (670.18) followed by Jeddah (510.60), Tabouk (334.57), Yanbu (304.78) and Taif (274.05). In 3936 larval collections (2950 positive SU), 10930 larva of 11 species (4 genera) and in 2820 light trap collections, 33108 adult of 19 species (6 genera) were collected. The relative abundance of the reported genera was examined based on the number of species and number of collected larvae and adults (Tab. 3). The compiled result of all localities revealed that: (1) Of the four larval genera, genus Culex was predominating (7: $63.64 \% \mathrm{sp}, 92.74 \%$ larva). The other three genera were Anopheles $(2: 18.18 \%$ sp., $1.99 \%$ larva), Stegomyia (1:9.09\% sp., $2.91 \%$ larva) and Culiseta (1:9.09\% sp., $2.36 \%$ larva). (2) Of the six adult genera, genus Culex was predominat- 
ing (11: $57.89 \%$ sp., $93.46 \%$ adult) followed by genus Anopheles (4: $21.05 \%$ sp., $0.60 \%$ adult). The other genera: Stegomyia (1:5.26\% sp., $2.18 \%$ adult), Ochlerotatus (1:5.26\% sp., $0.82 \%$ adult), Aedimorphus $(1: 5.26 \%$ sp., $<0.01 \%$ adult $)$ and Culesita (1:5.26\% sp., $2.94 \%$ adult).

More or less similar results were obtained by other workers in some localities of the western part of the Kingdom. Khater et al. (2013) carried out a survey in Makkah, Al-Baha and Jezan and collected 2766 larva of 21 species from six genera of which 52\% were Anopheles, $44.3 \%$ were Culex, $0.51 \%$ were Aedes and $3.1 \%$ were from three other genera. (Ochlerotatus, Lutzia and Uranotaenia). Mahyoub et al. (2015) reported that in Makkkah city, larvae of Culex genus were the most dominant in terms of geographical distribution followed in terms of density to genus Anopheles while larvae of genus Aedes were less in population. The wide spread and abundance of Culex larvae may be due to the fact that they can exploit a wide variety of aquatic habitats for their development and survival, and can tolerate highly polluted aquatic environment and relatively saline water (Alahmed, 2012).

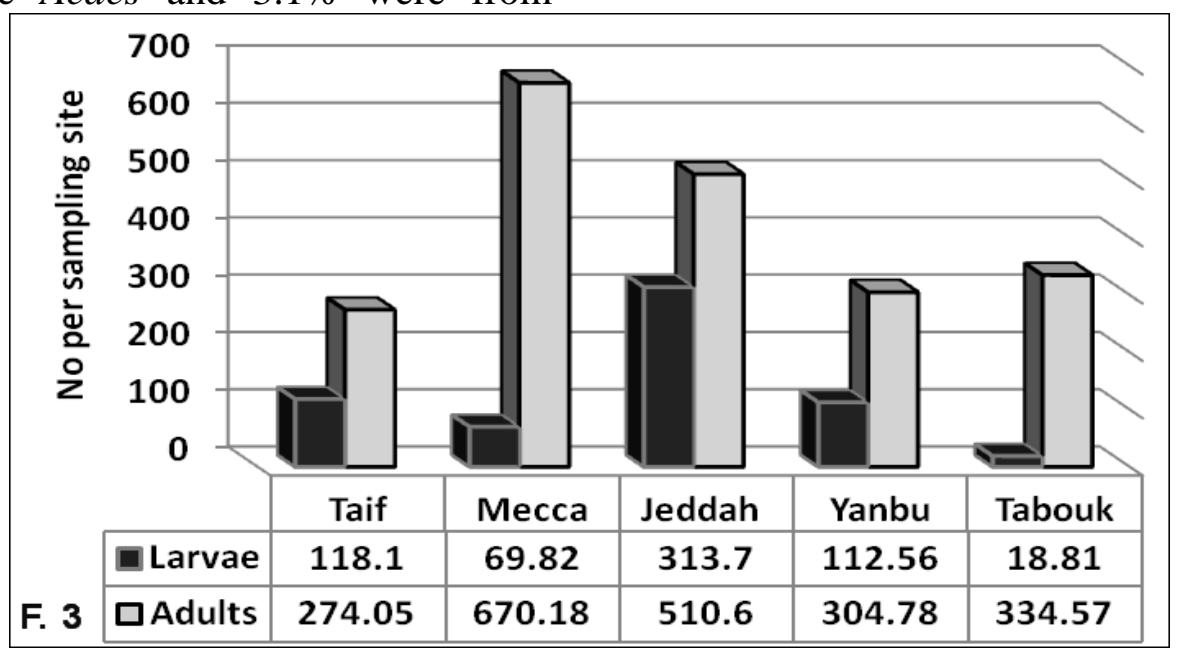

Fig. 3: Number of larvae and adults per sampling site for surveyed localities Table 3: Relative abundance of the reported mosquito genera

\begin{tabular}{|l|c|c|c|c|c|c|}
\hline \multirow{2}{*}{ Genus } & \multicolumn{2}{|c|}{ Species } & \multicolumn{2}{c|}{ Larvae } & \multicolumn{2}{c|}{ Adults } \\
\cline { 2 - 8 } & No & $\%$ & No & $\%$ & No & $\%$ \\
\hline Culex & 11 & 57.89 & 01051 & 92.74 & 30942 & 93.46 \\
\hline Anopheles & 4 & 21.05 & 217 & 1.99 & 200 & 0.60 \\
\hline Stegomyia & 1 & 5.26 & 318 & 2.91 & 721 & 2.18 \\
\hline Ochlerotatus & 1 & 5.26 & 0 & 0 & 270 & 0.82 \\
\hline Aedimorphus & 1 & 5.26 & 0 & 0 & 1 & $<0.01$ \\
\hline Culesita & 1 & 5.26 & 258 & 2.36 & 974 & 2.94 \\
\hline Total & \multicolumn{7}{|c|}{19} & \multicolumn{2}{c|}{10930} & \multicolumn{2}{c|}{33108} \\
\hline
\end{tabular}

The relative abundance of larval and adult species (\% collected from the total collection) was examined in the different studied localities (Tab. 4). The compiled results revealed that the $C x$. quinquefasciatus (47.11\% larva, $57.52 \%$ adult) and $C x$. pipiens (22.24\% larva, $27.42 \%$ adult) were the common species similar to previous reports from El Madina Region where $C x$. pipiens represented $59.3 \%$ of collected adults and $60 \%$ of larvae while $C x$. quinque- fasciatus represented $22.1 \%$ of adults and $20 \%$ of larvae (AI Ali et al, 2008) and Makkah where $C x$. quinquefasciatus adults (99.3\%) were predominating (Khater et al, 2013). As larvae, $C x$ pipiens (11.89\%), $C x$. theileri $(8.02 \%)$, St. aegypti and $C x$ tritaeniorynchus $(2.91 \%$ each), Cs. longiareolata $(2.36 \%)$ and An. multicolor (1.84\%) were less common. $C x$. perexiguus $(0.43 \%)$, An. d'thali $(0.15 \%)$ and Cx. torrentium $(0.14 \%)$ were rare species. As adults, the 
descending order of abundance was $C x \mathrm{si}$ tiens (3.91\%), Cs. longiareolata (2.94\%), St. aegypti (2.18\%), Cx. tritaeniorynchus (1.65\%), Cx. perexiguus (1.24\%), Oc. caspius $(0.82 \%), C x$. theileri $(0.69 \%), C x$. lacticinchus $(0.54 \%)$, Cx. sinaiticus $(0.42 \%)$,
An. multicolor $(0.35 \%)$, An. sergentii (0.14\%), An. d'thali (0.10\%), Cx. torentium (0.05\%), Cx. simposoni (0.02\%), An. fluviatilis $(0.01 \%), C x$. pusillus $(<0.01 \%)$ and Am. v. arabiensis $(<0.01 \%)$.

Table 4: Relative abundance of the reported mosquito larval and adult species

\begin{tabular}{|l|c|c|c|c|}
\hline \multirow{2}{*}{ Species } & \multicolumn{2}{|c|}{ Larvae } & \multicolumn{2}{c|}{ Adults } \\
\cline { 2 - 5 } & No & $\%$ & No & $\%$ \\
\hline Cx. pipiens & 2431 & 22.24 & 9077 & 27.42 \\
\hline Cx. perexiguus & 47 & 0.43 & 411 & 1.24 \\
\hline Cx. sinaiticus & & & 138 & 0.42 \\
\hline Cx. quinquefasciatus & 5149 & 47.11 & 19045 & 57.52 \\
\hline Cx tritaeniorynchus & 318 & 2.91 & 546 & 1.65 \\
\hline Cx. theileri & 877 & 8.02 & 227 & 0.69 \\
\hline Cx sitiens & 1300 & 11.89 & 1293 & 3.91 \\
\hline Cx. torrentium & 15 & 0.14 & 16 & 0.05 \\
\hline Cx. simposoni & & & 8 & 0.02 \\
\hline Cx. lacticinchus & & & 180 & 0.54 \\
\hline Cx. pusillus & & & 1 & $<0.01$ \\
\hline An. d'thali & 16 & 0.15 & 34 & 0.10 \\
\hline An. multicolor & 201 & 1.84 & 116 & 0.35 \\
\hline An. sergentii & & & 47 & 0.14 \\
\hline An. fluviatilis & & & 3 & 0.01 \\
\hline St. aegypti & 318 & 2.91 & 721 & 2.18 \\
\hline Oc. caspius & & & 270 & 0.82 \\
\hline Am. v. arabiensis & & & 1 & $<0.01$ \\
\hline Cs. longiareolata & 258 & 2.36 & 974 & 2.94 \\
\hline
\end{tabular}

Some of the reported mosquito species of the western coast during this study are implicated as vectors of diseases either in this part or in several other parts of the Kingdom (Tab. 5). Of the Culex mosquitoes, $C x$. pipiens and $C x$. quinquefasciatus, are the chief vectors of bancroftian filariasis, Wuchereria bancrofti in many parts of the world including the Middle East and Eastern Mediterranean countries (AI-Ali et al, 2008). The disease has been reported from the southwestern districts of the Kingdom. Omar (1996) identified W. bancrofti among expatriate workers from five SouthEast Asian countries in Abha and reported that the local $C x$. pipiens is highly susceptible to the parasite and concluded that this mosquito species may act as a potential vector of introduced bancroftian filariasis to Saudi Arabia. Haleem et al. (2002) reported three filarial cases from Saudi residences in Armed Forces Hospital, Riyadh. Jupp et al. (2002) and Miller et al. (2002) indicated that $C x$. tritaeniorhynchus and Am. v. arab- iensis are the main proven vectors of the Rift Valley Fever virus in the southern part of Saudi Arabia. In mid-September 2000, RVF outbreak began in Jizan and Yemen, and then extended northwards into Asir and $\mathrm{Al}$ Quenfadah. It was the first time to report RVF outside Africa and its first incursion into Saudi Arabia and Yemen (Miller et al, 2002; Jupp et al, 2002; Shoemaker et al, 2002). Seventy six people have died from an outbreak of Rift Valley fever and 408 people had contracted the disease (Ahmad, 2000). The outbreaks of RVF were reported since 1995 in the Tehama Red Sea coastal plateau in the western and southern regions, due to floods following heavy rainfall and agricultural activities that created ideal habitats for larvae of its vectors (Balkhy and Memish, 2003). Wills et al. (1985) isolated Sindbis virus, a human pathogen causing a dengue-like illness from $C x$. univittatus ( $C x$. perexiguus) in the Eastern Region. Besides, $C x$. pipiens was found to harbor West Nile Virus (WNV) in the examined mosquitoes 
from Al Madinah (Al-Ali et al, 2008). The author concluded that there is a potential danger of the transmission of WNV in $\mathrm{Al}$ Madinah especially by $C x$. pipiens. It was reported that Ae. aegypti (St. aegypti) is the primary established indigenous domestic vector of Dengue fever (DF) in Jeddah and Makkah (El-Badry and Al-Ali, 2010).

The virus was isolated for the first time from an adult in Jeddah in 1994 (Ahmed et $a l, 2011)$ and from February 1994 via December 2002 the total proved cases were 319 (Fakeeh and Zaki, 2003). Moreover, a total of 2357 laboratory confirmed cases were reported to the primary health care in Jeddah (Alzahrani et al, 2013). Ayyub et al, (2006) reported 39 out of $80(48.75 \%)$ cases admitted with suspected diagnosis of DF in a large public hospital in Jeddah from May 2004 till April 2005. Alwafi et al. (2013) analyzed dengue fever data collected by the Vector-Borne Disease Unit in the Ministry of Health from 2008 to 2012 and reported that in 2008, the incidence rate was 6.2 per 100,000 . This rate increased in 2009 to 110.6, then declined in 2010 to 62.95 . In 2011 it declined further to 56.5 and in 2012 to 37.6. Of the anopheline species, $A n$. sergentii is a secondary vector responsible for malaria transmission in southwest of the Kingdom (Al-Seghayer et al, 1999; Abdoon and Al-shahrani, 2003) and in the Eastern Province (Daggy, 1959; MOH, 1983) where An. arabiensis and An. stephensi act as the primary vectors in the two areas, respectively (Al-Seghayer et al, 1999). Malaria is endemic since 1900, and health reports showed that there is active transmission although at small level, with $<10 \%$ of the reported cases were locally-transmitted and the rest were imported (Khater et al, 2013). Malaria was highly endemic in the Southwest (Jizan and Asir) where $83 \%$ of the Kingdom total cases are reported (AlSeghayer et al, 1999). Moreover, An. fluviatilis is considered as secondary malaria vector in the Eastern Province (Daggy, 1959; $\mathrm{MOH}, 1983)$. An. multicolor is another important species in malaria transmission in other countries as well as in Saudi Arabia. The species is a suspected oases vector in Egypt (Kenawy et al, 1986) and North Africa (Zahar, 1974) and is regarded as a secondary malaria vector in some localities of Saudi Arabia (Abdoon and Alshahrani, 2003).

\begin{tabular}{|c|c|c|c|c|c|c|}
\hline Species & 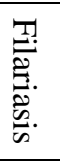 & 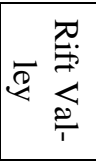 & 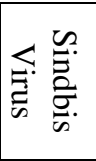 & 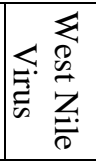 & 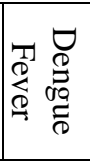 & \\
\hline Cx.pipiens & 0 & & & D & & \\
\hline Cx. quinquefasciatus & $\mathrm{O}$ & & & & & \\
\hline Cx. tritaeniorhynchus & & D & & & & \\
\hline Cx.perexiguus & & & Q & & & \\
\hline An. sergentii & & & & & & D \\
\hline An. fluviatilis & & & & & & O \\
\hline An. multicolor & & & & & & 0 \\
\hline St. aegypti & & & & & 으 & \\
\hline Am. v. arabiensis & & D & & & & \\
\hline
\end{tabular}

\section{Conclusion}

The diversity and abundance of different mosquito species, among which several vectors of diseases mainly malaria, Rift Valley fever, lymphatic filariasis and dengue fever have to draw attention to the western part of the Kingdom. Realizing that this area contains the holy places which are visited by millions of people from different countries all year round, the situation that pause a risk of transmission and more spread of such disease. So that control efforts have to be continued and intensified to overcome such situation. The results may be of importance for health officials in planning and implementing vector/disease control programs. 


\section{References}

Abdoon, AMMO, 2004: First record of three afrotopical Culex species (Diptera: Culicidae) in Saudi Arabia. Ann. Med. Entomol.13, 1/2:1-9.

Abdoon, AMMO, Alshahrani, AM, 2003: Prevalence and distribution of Anopheline mosquitoes in malaria endemic areas of Asir Region, Saudi Arabia. East. Mediterr. Hlth. J. 9, 3:240-7.

Abdullah, MAR, Merdan, AI, 1995: Distribution and ecology of the mosquito fauna in the southwestern Saudi Arabia. J. Egypt. Soc. Parasitol. 25, 3:815-37.

Ahmad, K., 2000: More deaths from Rift Valley fever in Saudi Arabia and Yemen. The Lancet, 356:1422.

Ahmed, AM, Shaalan, EA, Aboul-Soud, MA M, Tripet, F, Al-Khedhairy, AA, 2011: Mosquito vectors survey in the Al-Ahsaa district of eastern Saudi Arabia. J. Insect Sci. 11, 176:11-9.

Alahmed, AM, 2012: Mosquito fauna (Diptera: Culicidae) of the Eastern Region of Saudi Arabia and their seasonal abundance. J. King Saud Univ. Sci. 24, 1:55-62.

Alahmed, AM, Al Kuriji, MA, Kheir, SM, 2007: Distribution and habitat of mosquito larvae (Diptera: Culicidae) in Riyadh Region, Saudi Arabia. J. King Saud Univ. (Agric. Sci.) 9, 2:39-55.

Alahmed, AM, Al Kuriji, MA, Kheir, SM, Al Ahmedi, SA, Al Hatabbi, MJ, et al, 2009: Mosquito fauna (Diptera: Culicidae) and seasonal activity in Makkah Al Mukarramah Region, Saudi Arabia. J. Egypt. Soc. Parasitol. 39, 3:9911013.

Al Ahmed, AM, Al Kuriji, MA, Kheir, SM, Al Sogoor, DAD, Salama, HAS, 2010: Distribution and seasonal abundance of mosquitoes (Diptera: Culicidae) in the Najran Region, Saudi Arabia. Studia dipterologica 17, 1/2:13-27.

Al Ahmad, AM, Sallam, MF, Khuriji, MA, Kheir, SM, Azari-Hamidian, S, 2011: Checklist and pictorial key to fourth-instar larvae of mosquitoes (Diptera: Culicidae) of Saudi Arabia. J. Med. Entomol. 48, 4:717-37.

AI-Ali, KH, EI-Badry, AA, Eassa, AHA, AlJuhani, A M, Al-Zubiany, SF, et al, 2008: A study on Culex species and Culex transmitted diseases in AI-Madinah AI-Munawarah, Saudi Arabia. PUJ 1, 2:101-8.

Al Ashry, HA, Kenawy, MA, Shobrak, M, 2014: Fauna of mosquito larvae (Diptera: $\mathrm{Cu}-$ licidae) in Asir provence, Kingdom of Saudi Arabia. J. Egypt. Soc. Parasitol. 44, 1:171-84.
Al Ghamdi, K, Alikhan, M, Mahayoub, J, Afifi, ZI, 2008: Studies on identification and population dynamics of Anopheline mosquito from Jeddah, Saudi Arabia. Biosci. Biotech. Res. Commun. 1, 1:19 24.

Al-Hazmi, M, Ayoola, EA, Abdurahman, M, Banzal, S, Ashraf, J, et al, 2003: Epidemic Rift Valley Fever in Saudi Arabia: A clinical study of severe illness in humans. Clin. Infect. Dis. 36, 3:245-52.

Alikhan, M, Ghamdi, KA, Mahyoub, JA, 2014: Aedes mosquito species in western Saudi Arabia. J. Insect Sci. 14, 69: 7pp. Available online: http://www.insectscience.org/14.69

Al-Qabati, AG, Al-Afaleq, AI, 2010: Crosssectional, longitudinal and prospective epidemiological studies of rift valley fever in Al-Hasa Oasis, Saudi Arabia. J. Anim. Vet. Adv. 9, 2: 258-65.

Al-Seghayer, SM, Kenawy, MA, Ali, OTE, 1999: Malaria in the Kingdom of Saudi Arabia: Epidemiology and control. Sci. J. King Faisal Univ. (Special issue), 1:6-20.

Al-Tawfiq, JA, 2006: Epidemiology of travelrelated malaria in a non-malarious area in Saudi Arabia. Saudi Med. J. 27, 1: 86-9.

Alwafi, OM, McNabb, SJN, Memish, ZA, Assiri, A, Alzahrani, SH, et al, 2013: Dengue Fever in Makkah, Kingdom of Saudi Arabia, 20082012. Am. J. Res. Commun. 1, 11:123-39.

Alzahrani, AG, Al Mazroa, MA, Alrabeah, A M, Ibrahim, AM, Mokdad, AH, et al, 2013: Geographical distribution and spatio-temporal patterns of dengue cases in Jeddah Governorate from 2006-2008. Trans R. Soc. Trop. Med. Hyg. 107, 1:23-9

Ayyub, M, Khazindar, AM, Lubbad, EH, Barlas, S, Alfi, AY, et al, 2006: Characteristics of dengue fever in a large public hospital, Jeddah, Saudi Arabia. J. Ayub Med. Coll. Abbottabad. 18, 2:9-13

Aziz, AT, Al-Shami, SA, Mahyoub, JA, Hatabbi, M, Ahmad, AH, et al, 2014: An update on the incidence of dengue gaining strength in Saudi Arabia and current control approaches for its vector mosquito. Parasites Vectors 7, 1:258. Bakr, RFA, Nassar, MI, El-Barky, NM, Kotb, TF, Badrawy, H, et al, 2014: Prevalence of mosquitoes in Jazan Province, Saudi Arabia. Egypt. Acad. J. Biol. Sci. 7, 2:15-27.

Balkhy, HH, Memish, ZA, 2003: Rift Valley fever: an uninvited zoonosis in the Arabian peninsula. Int. J. Antimicrob. Agents 21, 2:153-7. 
Büttiker, W, 1981: Observations on urban mosquitoes in Saudi Arabia. Fauna of Saudi Arabia, 3:472-9.

Daggy, RH, 1959: Malaria in oases of eastern Saudi Arabia. Am. J. Trop. Med. Hyg. 8, 2:22391

El-Badry, AA, Al-Ali, KH, 2010: Prevalence and seasonal distribution of dengue mosquito, Aedes aegypti (Diptera: Culicidae) in Al Madinah Al-Munawwarah, Saudi Arabia. J. Entomol. 7, 2:80-8.

Elfadil, AA, Hasab-Allah, KA, Dafa-Allah, O M, Elmanea, AA, 2006: The persistence of Rift Valley fever in the Jazan region of Saudi Arabia. Rev. Sci. Tech. Off. Int. Epiz. 25, 3: 1131-6

El-Gilany, AH, Eldeib, A, Hammad, S, 2010: Clinico-epidemiological features of dengue fever in Saudi Arabia. Asian Pac. J. Trop. Med. 3, 3: 220-3.

Fakeeh, M, Zaki, AM, 2001: Virologic and serologic surveillance for dengue fever in Jeddah, Saudi Arabia, 1994-1999. Am. J. Trop. Med. Hyg. 65, 6:764-7.

Fakeeh, M, Zaki, AM, 2003: Dengue in Jeddah, Saudi Arabia, 1994-2002. Bull. WHO, 27: 13-8.

Flick, R, Bouloy, M, 2005: Rift Valley fever virus. Curr. Mol. Med. 5, 8: 827-34.

Glick JI, 1992: Illustrated key to the female Anopheles of southwestern Asia and Egypt (Diptera: Culicidae)'. Mosq. Syst. 24, 2:125-53.

Haleem, A, Al Juboury, M, Al Husseini, H, 2002: Filariasis: A report of three cases. Ann. Saudi Med. 22, 1/2:77-9.

Hammer, Ø, Harper, DAT, Ryan, PD, 2001: Past: Paleontological statistics software package for education and data analysis. Available from: http://www.nhm2.uio.no/norlex/past/Past.exe

Jupp, PG, Kemp, A, Grobbelaar, A, Leman, P, Burt, FJ, et al, 2002: The 2000 epidemic of Rift Valley fever in Saudi Arabia: mosquito vector studies. Med. Vet. Entomol. 16, 3:245-52.

Kenawy, MA, Beier, JC, El-Said, S, 1986: First record of malaria and associated Anopheles in El Gara Oasis, Egypt. J. Am. Mosq. Cont. Assoc. 2, 1:101-3.

Khan NA, Azhar, EI, El-Fiky, S, Madani, H H, Abuljadial, MA, et al, 2008: Clinical profile and outcome of hospitalized patients during first outbreak of dengue in Makkah, Saudi Arabia. Act Trop. 105, 1:39-44.

Khater, EI, Sowilem, MM, Sallam, MF, Ala- hmed, AM, 2013: Ecology and habitat characterization of mosquitoes in Saudi Arabia. Trop. Biomed. 30, 3:409-27.

Kheir, SM, Al Ahmed, AM, Al Kuriji, MA, Al Zubyani, SF, 2010: Distribution and seasonal activity of mosquitoes (Diptera: Culicidae) in $\mathrm{Al}$ Madinah Al Munwwarah Region, Saudi Arabia. J. Egypt. Soc. Parasitol. 40, 1: 215-27.

Madani, TA, Al-Mazrou, YY, Al-Jeffri, MH, Mishkhas, AA, Al-Rabeah, AM, et al, 2003: Rift Valley Fever epidemic in Saudi Arabia: Epidemiological, clinical, and laboratory characteristics. Clin. Infect. Dis. 37, 8:1084-92.

Mahyoub, JA, Al-Harbi, OS, Al-Ghamdi KM, Mangoud, AAH, Al-Solami, HM, 2015: Population dynamics of different mosquito genera and species in Makkah city, Saudi Arabia. Biosci. Biotech. Res. Comm. 8, 2:116-25

Mattingly, PF, Knight, KL, 1956: The mosquitoes of Arabia. Bull. Brit. Mus. (Nat. Hist.) Entomol. 4, 3:89-141.

Miller, BR, Godsey, MS, Crabtree, MB, Savage, HM, Al-Mazrao, YY, et al, 2002: Isolation and genetic characterization of Rift Valley Fever virus from Aedes vexans arabiensis, Kingdom of Saudi Arabia. Emerg. Infect. Dis. 8, 12: 1492-4.

MOH (Ministry of Health, Kingdom of Saudi Arabia) 1983: Malaria Control Programme in the Kingdom: Annual Report of Malaria Control Service (January-December 1982), 90 pp.

Omar, MS, 1996: A survey of bancroftian filariasis among South-East Asian expatriate workers in Saudi Arabia. Trop. Med. Int. Hlth. I, 2: 155-60.

Sebai, ZA, Morsy, TA, Zawahry, MI, 1974: A preliminary study on filariasis in Western part of Saudi Arabia. Castellania Tropenmed. Dermatol. Acron Verlag, Berlin 2, 12:263-6.

Shoemaker, T, Boulianne, AS, Rollin, PE, Swanepoel, R, Ksiazek, TG, et al, 2002: Genetic analysis of viruses associated with emergence of Rift Valley fever in Saudi Arabia and Yemen, 2000-2001. Emerg. Infect. Dis. 12:1415-20

Warrell, DA, 1993: Leishmaniasis, malaria and schistosomiasis in Saudi Arabia. Saudi Med. J. 14:203-8.

Wills, WM, Jakob, WL, Francy, DB, Oertley, RE, Anani, E, et al, 1985: Sindbis virus isolations from Saudi Arabian mosquitoes. Trans. R. Soc. Trop. Med. Hyg. 79, 1:63-6.

Zahar, AR, 1974: Review of the ecology of malaria vectors in the WHO Eastern Mediterranean Region. Bull. WHO 50, 5:427-40 